\title{
Medida qualitativa de cor e de iluminantes baseada na percepção humana
}

\author{
Fabiana R. Leta, DSc \\ fabiana@ic.uff.br \\ Universidade Federal Fluminense \\ Programa de Pós-Graduação em Engenharia Mecânica \\ Rio de Janeiro, Brasil \\ Márcia P. Velloso, DSc \\ marcia@pimentavelloso.org \\ Universidade Federal Fluminense \\ Programa de Pós-Graduação em Engenharia Civil \\ Rio de Janeiro, Brasil
}

\begin{abstract}
Com o desenvolvimento da propaganda, a cor passou a ser um diferencial tanto para o reconhecimento de uma dada marca, como para a sensação de um bom produto. As indústrias e companhias precisam garantir a qualidade de seus produtos e serviços, e neste contexto observa-se a necessidade de expressar apropriadamente a cor dos produtos. Dentre os muitos itens a serem controlados, pode-se distinguir a qualidade da cor do produto e conseqüentemente a percepção apropriada desta para o consumidor. De fato, em muitos casos nota-se uma grande diferença entre as cores projetadas, as cores produzidas e as cores percebidas pelos usuários finais. A indústria deve ser capaz de atender às expectativas do consumidor quanto à percepção, garantindo a constância das cores de seus produtos. Este assunto preocupa vários setores industriais tais como: automobilístico, manufatureiro, têxtil, de mobiliário urbano e doméstico, de alimentação, de artes cênicas e gráficas, de tintas, cosméticos etc; sendo, além disso, importante para qualquer setor que pretenda desenvolver produtos que dependam de apelos visuais. A proposta deste artigo é apresentar uma metodologia para estudar como o ser humano percebe e expressa as características de cores dos produtos em situações reais. Este trabalho avalia diferentes cores sob diferentes fontes de iluminação. Com a obtenção futura de medidas quantitativas, tornarse-á possível criar um modelo de percepção de cor pelo ser humano em produtos comerciais. Neste contexto, este artigo apresenta alguns resultados de uma pesquisa em percepção de cores. Os resultados apresentados podem ajudar projetistas a ajustar a cor de seus produtos de acordo com esta percepção.
\end{abstract}

Palavras-chave: percepção de cor; iluminação; calorimetria.

The perception of colours is very important to recognize commercial products. It is also significant when the matter is to feel how good is a certain product. In this context we observe the need of present properly products colour. Industries and companies must assure the quality of their products and services. Among the several items to be controlled we can remark the quality of the colour product and consequently its appropriate perception for the consumer. In fact, in many cases we notice a great difference between the projected colours, the produced ones and the colours perceived by the final users. The industry should be capable to assist to the consumers' expectations guaranteeing the constancy of their products colour. This subject affects several industrial sectors like: automobiles, manufacturing, textile, urban and domestic furniture, food, design, scenic and graphic arts, paints, cosmetics, etc. The proposal of this paper is to present a methodology to study how the human being perceive and express the characteristic of product colours in realistic conditions. This paper deals with different colour hues, submitted to different lighting. Acquiring those quantitative measurements, we can create a model of human-like colour perception of commercial product. In this context, this paper presents some results of a research in colour vision. We consider specially the colour perception in different illuminations. The presented results may help designers to adjust their product colour according to human colour difference perception.

Keywords: color perception; lightining; colour metrology. 


\section{Introdução}

As indústrias e empresas precisam a todo o momento garantir a qualidade de seus produtos e serviços. Entre os diversos itens a serem controlados pode-se destacar a qualidade da cor e conseqüentemente a adequada percepção desta pelo consumidor. Em muitos casos percebe-se uma grande diferença entre as cores projetadas, aquelas produzidas e as de fato percebidas pelos usuários finais. A indústria deve ser capaz de atender às expectativas do consumidor, garantindo a constância da cor de seus produtos. Esta questão preocupa diversos setores, cabendo citar as indústrias e empresas de: automóveis, tecidos, mobiliário urbano e doméstico, alimentos, design, artes cênicas e gráficas, tintas e revestimentos, cosméticos, entre outras. Estudos nesta área são importantes para qualquer setor que pretenda desenvolver produtos que dependam de apelos visuais.

Geralmente, a classificação de cor dos objetos é feita através de instrumentos em experiências controladas de laboratórios. É sabido que a classificação de cor e seu agrupamento envolvem também avaliações subjetivas que a cor fornece. A ambigüidade do ser humano para expressar se uma cor é mais clara, mais escura, mais esverdeada, torna irreal o uso de um processo determinístico para classificação de cor. Em termos de resultados, as fórmulas de cor usadas hoje não contemplam este tipo de linguagem. Alguns programas de agrupamento de cor usam aproximações de diferenças de cor que são tomadas como cores vizinhas e que mantêm diferença de cor mínima.

Neste contexto, gradações são usadas para as cores, de modo a tornar mais realista a modelagem da percepção e a classificação delas. Uma aproximação interessante para operar com os resultados obtidos consiste no uso de Lógica Nebulosa (LETA e ARAÚJO, 2000). O conceito de Lógica Nebulosa foi introduzido por Lotfi Zadeh. Inicialmente apresentado como uma extensão da lógica tradicional, um sistema de Lógica Nebulosa é baseado em uma proposição lógica que não é necessariamente verdadeira ou falsa, mas possui, na realidade, graus de verdade (COX, 1994). Quando diz-se que o tempo está "ensolarado" não quer dizer que não há nuvens. Da mesma maneira, em um tempo nublado pode-se ter sol. Normalmente, aceita-se como ensolarado um céu com até $20 \%$ ou $30 \%$ de nuvens. Como, então, podem-se definir os limites destas proposições? Pode ser dito que, quando o ser humano usa tais condições que ele infere um grau de verdade. Os valores que definem o grau de verdade de uma proposição podem não ser conscientes, mas de algum modo definidos pelo contexto social, lingüístico, ou por uma base de referência experimental. Isto é o que se observa na classificação de cores feita pelo consumidor.

A sensação da cor depende da iluminação, do sistema de visão humana e da bagagem de conhecimento e vivência do indivíduo, que pode levar a percepções diferenciadas da cor dos objetos observados.

Este artigo apresenta uma metodologia para avaliar a cor sob iluminantes levemente diferentes, envolvendo pesquisa qualitativa baseada em percepção humana subjetiva. A meta principal desta pesquisa é estudar a forma como um grupo selecionado de pessoas percebe a cor de um objeto e como este grupo descreve isto verbalmente. A metodologia consiste em apresentar um número de diferentes amostras previamente escolhidas aos observadores selecionados. Estas amostras são submetidas a iluminantes diferentes, e o grupo, constituído de estudantes universitários jovens, realiza as observações.

Para tanto, as pesquisas, que vêm sendo desenvolvidas, envolvem duas linhas paralelas de investigação. A primeira tem por objetivo estabelecer uma classificação de cores, baseada nas características atribuídas pela percepção humana e a segunda, avaliar a percepção de diversos iluminantes e seus efeitos sobre o ser humano.

O estudo de percepção de cor é um assunto importante no segmento da visão de cor, especialmente ao se avaliar a influência de iluminações comerciais. Assim, os resultados podem ser usados em aplicações industriais.

\section{Modelos de Percepção de cor}

As fórmulas de cor estão sempre associadas a um chamado modelo de cor. Para provar a ambigüidade relativa ao fenômeno da cor, pode ser observado que existem pelo menos 15 modelos de cor cientificamente aceitos. Desde a Antigüidade, o homem tenta determinar a cor, tanto para observações científicas quanto para realçar objetos. A cor pode ser medida através de um sólido onde a luminosidade ou brightness (mais clara, mais escura), a saturação ou chroma (mais saturada ou pura, menos saturada ou impura) e o matiz ou hue (a cor em si, ou o chamado tom) seriam os eixos coordenados (JACKSON, MACDONALD e FREEMAN, 1994).

Com o passar do tempo, foi verificado que os seres humanos percebiam a cor de um modo não-linear. Então, cientistas tentaram aproximar os modelos práticos, de cor e de diferença de cor, através de sólidos não-lineares, como os de forma elíptica. Estas 
fórmulas continuam a ser testadas e ainda não existe um modelo de diferença de cor que contemple a totalidade dos casos (GIORGIANNI e MADDEN, 1998).

Algumas fórmulas de diferença de cor, tais como a chamada CMC (1:c), levam em consideração a proporcionalidade entre as escalas de luminosidade e a saturação da cor e ainda ajustam alguns de seus coeficientes com as variações decorrentes de acuidades de observação dos dados experimentais e de características da cor. Tais ajustes levam a pensar que, embora consiga-se determinar matematicamente uma quantidade numérica para expressar a diferença de cor, persiste a ambigüidade em expressar diferenças pequenas ou sutis que, infelizmente, a métrica tradicional não consegue distinguir.

Entre as fórmulas de cor hoje conhecidas, destacamse as da CIE (Commision Internationale de L'Eclairage de 1931-1964), a CIELAB, CIELUV, CIELCH, CMC (1:c), RLab (M.D. FAIRCHILD, Color Appearance Models, Addison Wesley Longman, 417p., 1997). Cada uma delas tem faixas específicas de aplicação e uso. Algumas empresas basearam-se nas fórmulas consagradas e editaram as suas próprias, com metodologia e treinamento dos avaliadores. Exemplos disso são as fórmulas de diferença de cor da $J \& P$ Coats (Linhas Corrente no Brasil) e Marks \& Spencer (loja de departamentos inglesa).

A avaliação da diferença de cor, como realizada pelas indústrias, aceita a linearidade entre as medidas de diferenças e as escalas perceptíveis. No caso de diferenças muito pequenas (valores tênues de tom) é muito difícil aplicar esta relação linear de um modo satisfatório.

Apesar de instrumentos poderem medir o estímulo de cor em termos de sua distribuição espectral, o sistema de visão humano não interpreta o estímulo de cor comparando cada estímulo em termos de comprimento de onda. O sistema de visão humano processa a resposta de três tipos de

fotorreceptores (cones) contidos na retina. Devido a esta característica, distribuições espectrais bem distintas podem parecer cores idênticas para o ser humano (GIORGIANNI e MADDEN, 1998).

A sensação de cor envolve, além da luz e do sistema de visão humana, a vivência do indivíduo, que pode induzir a diferentes percepções de cor nos objetos observados. Um papel pode ser considerado branco, independentemente da fonte de luz, mesmo que pareça amarelado, apesar da variação da fonte de luz alterar significativamente a leitura das cores.
A percepção humana de cores é ainda influenciada pela memória do observador. Observa-se que a memória do ser humano para certas cores não é muito rica. A menos que dois objetos de cores semelhantes sejam apresentados lado a lado, o observador terá dificuldade de dizer se eles são da mesma cor ou não. A cor em uma imagem é interpretada de acordo com experiências e memórias. Por essa razão quando é atribuído um nome a uma cor, é feita uma associação a algum objeto de cor similar. Assim, é comum ouvir denominações como azul-marinho, azul do céu, verdepiscina, amarelo-ouro etc.

Existem incontáveis características que podem ser associadas às cores. Uma dada cor pode ser vívida, bonita, forte, clássica, moderna, tranqüila, intensa etc. De acordo com o observador, a mesma cor pode ter características diferentes. Não se pode esperar a mesma resposta entre crianças e adultos, entre pessoas com baixo e alto grau de instrução e entre homens e mulheres. Pode-se, então, notar a complexidade envolvida na avaliação da percepção da cor pelo ser humano, especialmente quando pretende-se propor um modelo de classificação realista de cor. Ao associar-se a esta avaliação a variação da fonte de luz, aumentar-se-á sua dificuldade, especialmente em objetos comerciais que não são padrões de cor.

\section{Iluminantes}

A iluminação tem um papel fundamental na análise da cor, o que pode ser observado em situações cotidianas, como ao comprar uma roupa numa loja (com iluminação específica) o consumidor perceber uma cor e ao sair com a roupa "à luz do dia”, o mesmo perceber uma nova tonalidade.

Devido aos diferentes tipos de pós-fluorescentes, alguns conceitos fazem-se presentes. Entre eles podem-se destacar: (1) índice de reprodução de cor (IRC); (2) a intensificação de cor; (3) a temperatura de cor; (4) a intensidade luminosa; (5) a eficiência e (6) o consumo.

Considerando a questão da iluminação, percebe-se que tradicionalmente o consumidor escolhe entre lâmpada incandescente ou fluorescente. Entretanto, em 2001, no Brasil, em função de um racionamento de energia baseado em cotas de consumo, houve uma mudança radical nos critérios de escolha. Isto fez com que os consumidores trocassem as lâmpadas incandescentes por lâmpadas fluorescentes compactas. A partir de então a escolha da iluminação pelo consumidor passou a envolver os conceitos de "temperatura de cor" e "intensidade". Onde a temperatura de cor foi classificada pelos vendedores e consumidores como "luz azulada" ou "luz amarelada". 
Alguns chegam a discriminar as lâmpadas como "mais ou menos azuladas" ou "muito ou pouco azuladas". No caso das lâmpadas fluorescentes tubulares, o consumidor não especifica a temperatura de cor nem a potência, e sim suas dimensões. Atualmente, por uma razão simplesmente de estética, muitos consumidores procuram pela lâmpada $\mathrm{T} 8$, usando a nomenclatura "a mais fina". O conceito de "reprodução de cor" ainda é desconhecido de forma consciente.

A observação de cor é uma conseqüência da parcela de luz refletida pelo objeto. Ao se incidir luz sobre um objeto, este absorve todas as frequiências que ele, objeto possui, e reflete aquelas que não possui. Então, de acordo com o iluminante, o objeto refletirá uma quantidade maior ou menor de frequiências, alterando com isso a percepção de sua cor.

O iluminante natural é a luz solar, que varia a cada hora do dia, a cada dia do ano e de acordo com a latitude. Para uniformizar a observação de cor, em 1931 a CIE adotou iluminantes padrões para colorimetria. Segundo Lozano, "neste momento a técnica só permitia a realização prática de lâmpadas de tungstênio, com as condições de reprodutibilidade e exatidão necessárias; tendo como meta tomar a luz solar como iluminante padrão por excelência, definiu-se o iluminante A que corresponde à luz emitida por uma lâmpada de filamento de tungstênio à temperatura de cor de 2857K' (LOZANO, 1978). Posteriormente, a CIE recomendou os iluminantes $\mathbf{D}$ e $\mathbf{C}$, que são obtidos mediante a filtragem, por filtros líquidos, do iluminante A. O iluminante $\mathbf{B}$ corresponde à luz solar média com componente de céu ao meio dia, cuja temperatura de cor é de 4870K. O iluminante $\mathbf{C}$ está associado à luz média diurna para um céu completamente coberto à temperatura de cor de 6770K. Em 1967, a CIE recomendou o iluminante $\mathbf{D}_{65}$ correspondente à irradiação solar para uma temperatura de cor de $6500 \mathrm{~K}$.

Temperatura de cor associada é uma característica do iluminante independente do conceito de índice de reprodução de cor. $\mathrm{O}$ uso do conceito temperatura de cor surgiu com a indústria siderúrgica, devido à importância da temperatura no processo de obtenção do aço. Desta observação foi obtida uma escala de cor associada à temperatura do aço. Nesta escala, quanto mais amarela, mais baixa é a temperatura, e, quanto mais azulada, maior a temperatura. Como exemplo pode-se avaliar uma lâmpada incandescente, com temperatura de cor associada de $2700 \mathrm{~K}$ e uma lâmpada fluorescente compacta, com temperaturas de cor variando de $3000 \mathrm{~K}$ (cor amarela) a $4500 \mathrm{~K}$ e $6500 \mathrm{~K}$, sendo a de $6500 \mathrm{~K}$ a mais azulada entre elas. A temperatura de cor tem a sua explicação física através do estudo do "corpo negro" (Lei de Win).

Um outro conceito, importante no estudo de iluminantes é o índice de reprodução de cor (IRC). O IRC é a variação que se observa a partir da visão de cor dos objetos sob o iluminante em estudo, em relação a um iluminante padrão. A grande variedade de lâmpadas de descarga dá lugar à modificação das cores, quando comparada com a observada normalmente com os iluminantes convencionais (luz natural ou luz de filamento incandescente). O IRC é definido como $100 \%$ para lâmpadas incandescentes e, atualmente, têm-se lâmpadas de descarga (fluorescentes, sódio, multivapor etc.) com IRC desde $10 \%$ até $98 \%$.

As lâmpadas comerciais, não incandescentes, emitem um espectro muito diferente da lâmpada incandescente, que é a que mais se aproxima do espectro solar.

Uma observação interessante, segundo Lozano (1978), refere-se à definição de luz branca. " $E$ difícil definir o que é luz branca. A forma acadêmica seria dizer que é toda a luz neutra ou não seletiva. Isto é: que seu espectro tem igual intensidade em todo o âmbito visível. Tais luzes praticamente não existem. Por outro lado, a impressão de branco pode-se obter com a soma de três luzes espectrais puras devidamente escolhidas. Precisamente a antítese de um espectro contínuo e uniforme. Branco, em relação a luzes, é essencialmente um atributo psicológico, tanto mais quando é possível aceitar como brancas luzes de distintos matizes depois de um dado processo de adaptação, ou de um contraste estipulado. E ainda, sendo seletiva, observar a luz. percebendo-a como se não o fosse". Este aspecto corrobora as observações feitas anteriormente, no item sobre modelos de percepção de cor.

\section{Metodologia}

\subsection{Aspectos Gerais}

A metodologia adotada envolve a escolha de um grupo de amostras (objetos comerciais), que foi apresentado para observadores, sob condições variadas de iluminação. Os testes foram realizados em uma cabine dupla com duas fontes de luz, aparentemente semelhantes, mas com índice de reprodução de cor diferentes. Estas cabines consistem em ambientes controlados, onde a única iluminação que afeta as amostras advém das lâmpadas escolhidas. Na parte superior da cabine, apresentam-se também os objetos submetidos à fonte de luz não controlada, luz ambiente. Nas Figuras 1 e 2 apresentam-se, respectivamente, a vista esquemática superior e lateral da cabine de 


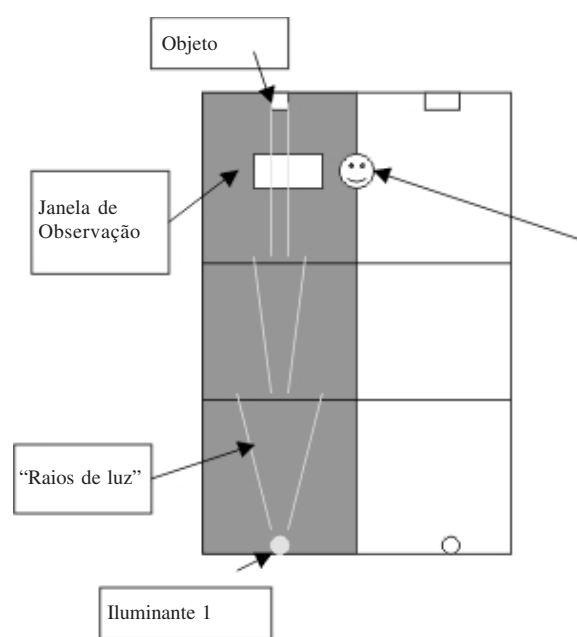

Figura 1 - Vista esquemática superior da cabine

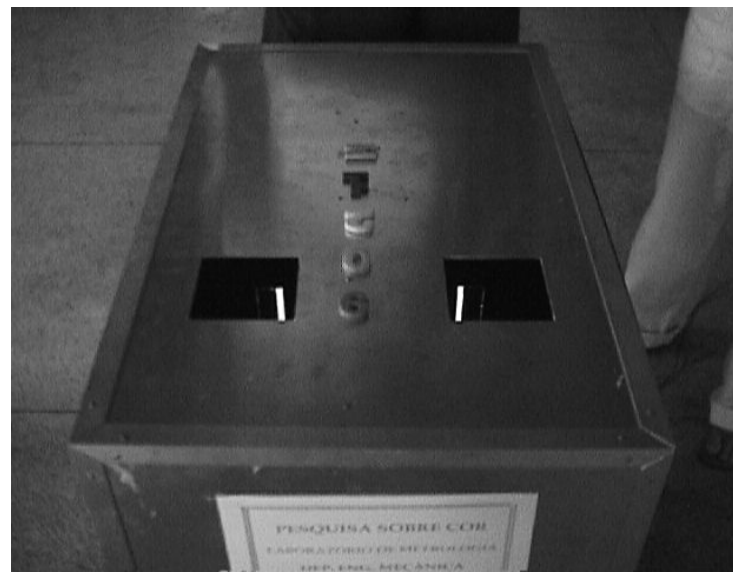

Figura 3 - Posicionamento dos iluminantes

teste. Na Figura 3 pode-se observar o posicionamento dos dois iluminantes (não observável pelo avaliador), e, na Figura 4 a visão do experimento pelo avaliador.

Para controlar esta avaliação foram apresentadas palavras comuns, não técnicas, adotadas usualmente pelos consumidores para descrever as cores. Além das cores, apresentou-se uma série de características de percepção e gosto para serem associadas a estas cores. Estas características foram escolhidas a partir da realização de um brainstorm, aplicado em um grupo de sete estudantes, dois professores e um técnico de laboratório.

O grupo de observadores consistiu de 82 estudantes da universidade, com idades entre 18 e 25 anos, pertencendo a este total 14 mulheres. Neste grupo havia um observador com deficiência visual (daltonismo) e dois que não distinguiam tons suaves de cor.

Para cada cor o observador atribuía uma escala que variava de 1 até 5 às características de percepção e

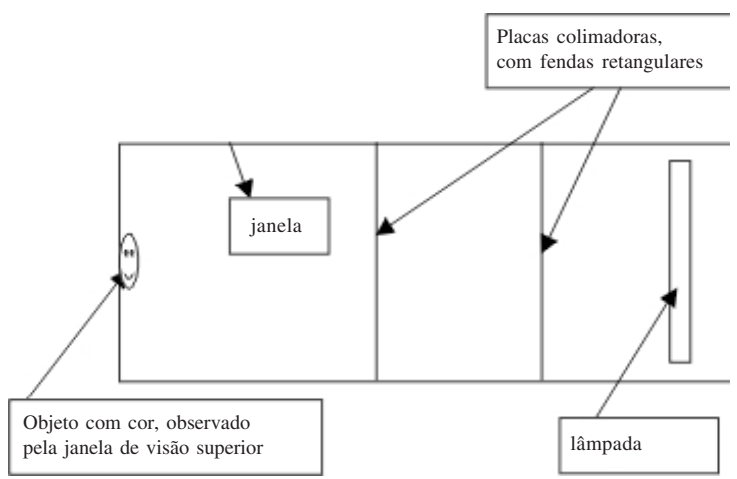

Figura 2 - Vista esquemática lateral da cabine

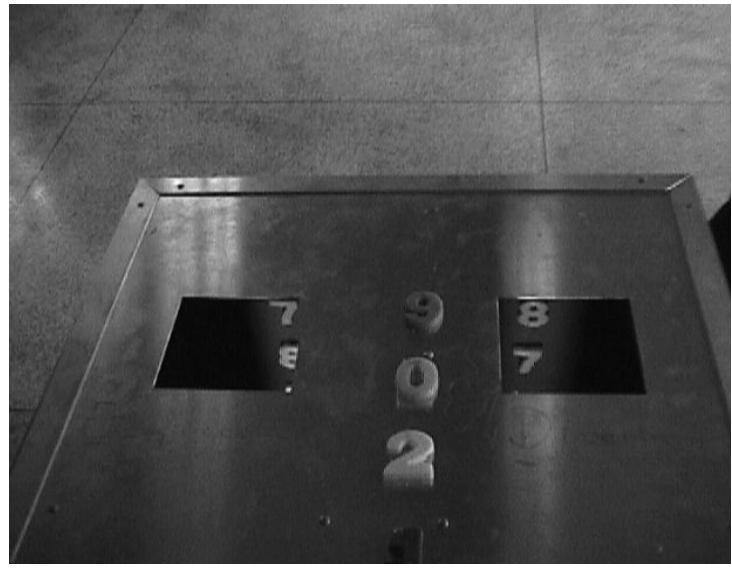

Figura 4 - Visão da caixa pelo avaliador

gosto. Esta escala consistia nos seguintes termos: "não é realmente", "não é muito", "parece”, "é bastante" e "é exatamente".

Foram consideradas as freqüências de ocorrência mais representativas, isto é, aquelas cujo desvio padrão era menor do que $5 \%$.

Os testes foram realizados em cabine dupla com iluminantes diferentes. Para cada iluminante foram contabilizadas as qualidades da cor percebidas e não percebidas.

\subsection{Avaliação quanto às cores}

Dezesseis características de cor foram então selecionadas, tomando por base termos adotados usualmente e/ou regionalmente por consumidores. As características escolhidas foram: vívido, intenso, ofuscante, apagado, claro, forte, escuro, neutro, suave, chique, romântico, tranqüilo, feminino, brega, 
bonito e moderno. Destas, as oito primeiras qualidades são de percepção e as outras oito são relativas ao gosto do indivíduo.

O objetivo consistiu em apresentar uma grande variedade de termos e analisar como as pessoas atribuem as características de cores aos objetos. Algumas destas características têm interpretações similares e outras têm interpretações opostas. As respostas obtidas correspondem à percepção do grupo com relação às cores dos objetos. Uma vez sendo obtidas medidas qualitativas de cor, torna-se possível reproduzir e modelar a interpretação humana de cor em produtos comerciais.

As condições em que o ser humano observa as cores no mundo real, no dia-a-dia, são muito diferentes das condições estabelecidas pelo sistema CIE. Em condições laboratoriais, a cabine é construída com fonte de luz específica e padrão, e um conjunto padronizado de cores é utilizado. No mundo real tem-se uma variedade de objetos, em tamanhos e formas diferentes, submetidos a uma variedade de fontes de luz. Existem muitos fatores que afetam a aparência da cor em uma imagem. As condições ambientais e a própria complexidade da imagem podem influenciar esta aparência significativamente.

As cores usadas para avaliação foram: ciano, azulmarinho, amarelo, laranja e magenta. Intencionalmente as cores escolhidas não eram cores puras, pois não se pretendia induzir a denominação da cor. Os objetos foram também escolhidos de modo que os observadores não fizessem qualquer associação de cor com a forma, o que poderia acontecer se fosse apresentado, por exemplo, uma maçã, que naturalmente seria associada à cor vermelha ou verde, jamais azul (LETA, ARAÚJO e VELLOSO, 2002).

\subsection{Avaliação quanto ao iluminante}

Além de observar as características atribuídas às cores, esta pesquisa teve a intenção de avaliar a cor e suas qualidades, quando era alterada a fonte de luz. Os objetos foram apresentados em três situações diferentes: a primeira, na luz ambiente (com iluminação variável); a segunda, com fonte de luz do tipo Chroma 50 (GE 20W, 5000K, IRC 92) e a última denominada Duramax Super Luz do Dia (GE 20W, $5250 \mathrm{~K}$, IRC 68). As duas últimas fontes de luz foram escolhidas porque correspondem a fontes comuns comerciais e porque visualmente possuem temperatura de cor semelhante, embora tenham diferentes índices de reprodução de cor.

Foram selecionadas, a partir de um brainstorm, seis características para avaliação dos iluminantes: brilhante, agradável, colorido, iluminado, apagado e bonito.

\section{Resultados}

\subsection{Quanto à cor}

Nas experiências realizadas, cinco cores foram apresentadas, denominadas pelos observadores como: rosa, laranja, amarela, azul e ciano. Alguns observadores atribuíram outros nomes para estas cores, tais como: azul piscina, azul claro, azul escuro, coral, azul-marinho etc.

Na Tabela 1 podem ser observadas as possibilidades de combinação de cor $x$ escala $x$ qualidade, apresentadas para os observadores.

Tabela 1 - Possibilidades de combinação de cor x escala x qualidade

\begin{tabular}{|c|c|c|}
\hline Cor & Escala & Qualidade \\
\hline $\begin{array}{c}\text { Ciano } \\
\text { Azul } \\
\text { Marinho } \\
\text { Amarelo } \\
\text { Laranja } \\
\text { Magenta }\end{array}$ & $\begin{array}{c}\text { Não é realmente } \\
\text { Não é muito } \\
\text { Parece } \\
\text { É bastante } \\
\text { É exatamente }\end{array}$ & $\begin{array}{l}\text { Vívida, intensa, } \\
\text { ofuscante, } \\
\text { apagada, clara, } \\
\text { forte, escura, } \\
\text { neutra, suave, } \\
\text { chique, } \\
\text { romântica, } \\
\text { tranqüila, } \\
\text { feminina, brega, } \\
\text { bonita e moderna }\end{array}$ \\
\hline
\end{tabular}

Na análise da amostra submetida à luz ambiente, nota-se que existe uma tendência à seguinte avaliação de cor: a maioria das respostas caracterizou a qualidade da cor usando a escala "parece", com uma distribuição simétrica entre "não é realmente" e "é exatamente". As exceções ocorreram nas seguintes características: apagada $(62,3)$, ofuscante $(42,13)$, romântica $(41,12)$, moderna $(9,46)$, escura $(61,11)$ e brega $(59,6)$, onde o par $(x, y)$ significa o número de respostas do tipo ("não é", "é”). Cabe observar que o conceito de "não é" passou a agregar os seguintes termos: "não é realmente" e "não é muito", enquanto que o conceito "é" passou a englobar, por sua vez, os termos: "é bastante" e "é exatamente".

Nas Figuras a seguir tem-se a comparação das qualidades associadas às cores dos objetos sob as fontes de luz controlada, Duramax e Croma 50. Os gráficos apresentados nas Figuras 5 e 6 correspondem àquelas qualidades não observadas, enquanto que nas Figuras 7 e 8 têm-se as qualidades observadas. Os gráficos estão agrupados dois a dois para permitir a comparação entre as duas fontes dos dados obtidos. Na Tabela 2 apresenta-se a legenda de cores correspondente às Figuras 5 a 8. 
Tabela 2 - Legenda das cores das figuras 5 à 8

\begin{tabular}{|c|c|c|c|c|c|}
\hline Símbolo & 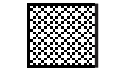 & $\approx$ & 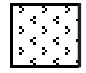 & 17 & $\operatorname{sgs}$ \\
\hline Cor & Amarelo & $\begin{array}{c}\text { Azul } \\
\text { Marinho }\end{array}$ & Ciano & Laranja & Magenta \\
\hline
\end{tabular}

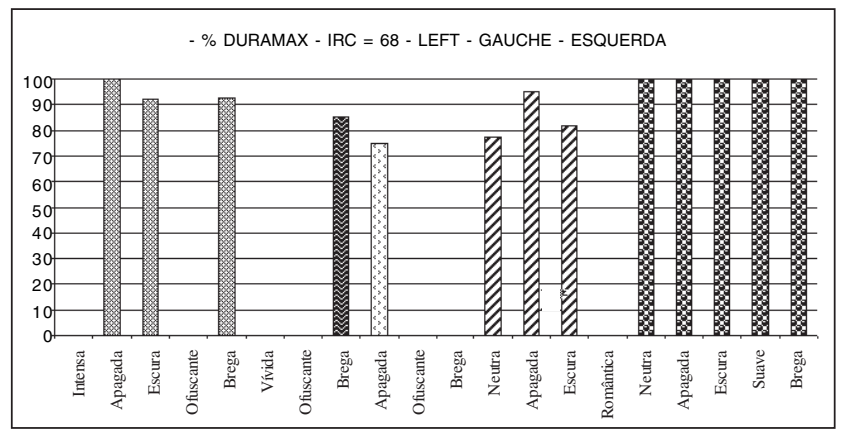

Figura 5 - Comparação das qualidades não observadas no iluminante Duramax

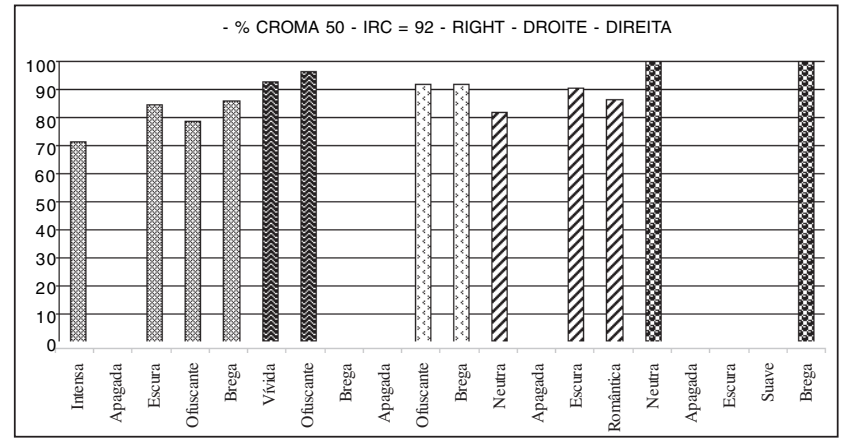

Figura 6 - Comparação das qualidades não observadas no iluminante Croma 50

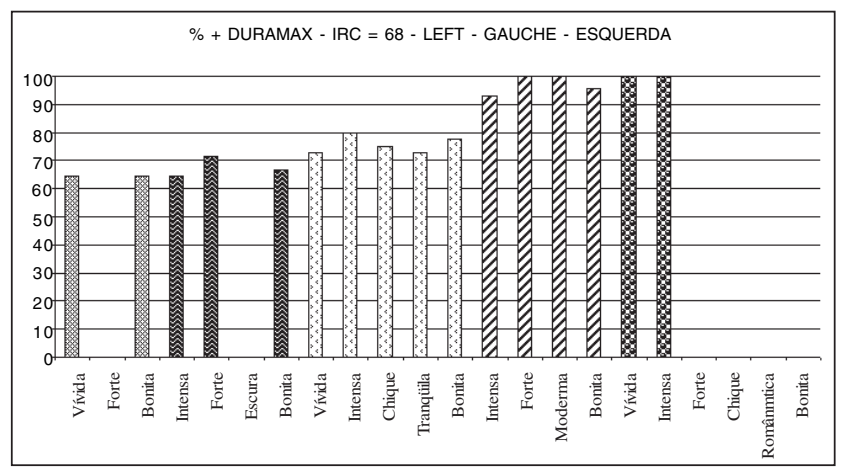

Figura 7 - Comparação das qualidades observadas no iluminante Duramax

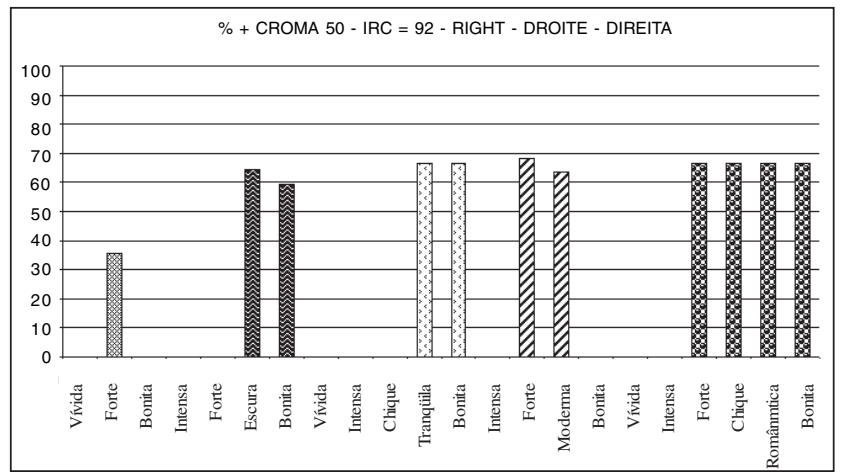

Figura 8 - Comparação das qualidades observadas no iluminante Croma 50 
Analisando-se os gráficos apresentados nas Figuras 5 a 8 pode-se destacar, nas Tabelas 3 e 4 as qualidades que não são percebidas para cada cor, que dependem e que não dependem do iluminante. Já nas Tabelas 5 e 6, observam-se as qualidades que são percebidas para cada cor, que dependem e que não dependem do iluminante.

Tabela 3 - Qualidades para cada cor que não são percebidas de acordo com o iluminante

\begin{tabular}{l|l|l}
\hline & \multicolumn{1}{|c|}{ Duramax } & \multicolumn{1}{c}{ Croma 50 } \\
\hline Amarelo & Apagada & $\begin{array}{l}\text { Intensa, } \\
\text { ofuscante }\end{array}$ \\
\hline Azul Marinho & Brega & $\begin{array}{l}\text { Vívida, } \\
\text { ofuscante }\end{array}$ \\
\hline Ciano & Apagada & Ofuscante, brega \\
\hline Laranja & Apagada & Romântica \\
\hline Magenta & $\begin{array}{l}\text { Apagada, } \\
\text { escura, suave }\end{array}$ & \\
\hline
\end{tabular}

Tabela 4 - Qualidades para cada cor que não são percebidas independente do iluminante

\begin{tabular}{l|c}
\hline & Duramax/Croma 50 \\
\hline Amarelo & Brega, escura \\
\hline Azul Marinho & - \\
\hline Ciano & - \\
\hline Laranja & Escura, neutra \\
\hline Magenta & Brega, neutra \\
\hline
\end{tabular}

Tabela 5 - Qualidades para cada cor que são percebidas de acordo com o iluminante

\begin{tabular}{l|l|l}
\hline & \multicolumn{1}{|c}{ Duramax } & \multicolumn{1}{c}{ Croma 50 } \\
\hline Amarelo & Vívido, bonita & Forte \\
\hline Azul Marinho & Intensa, forte & Escuro \\
\hline Ciano & $\begin{array}{l}\text { Vívida, intensa, } \\
\text { chique }\end{array}$ & $\begin{array}{l}\text { Tranqüila, } \\
\text { bonita }\end{array}$ \\
\hline Laranja & Intensa, bonita & Forte, moderna \\
\hline Magenta & Vívida, intensa & $\begin{array}{l}\text { Forte, chique, } \\
\text { romântica, } \\
\text { bonita }\end{array}$ \\
\hline
\end{tabular}

Tabela 6 - Qualidades para cada cor que são percebidas independente do iluminante

\begin{tabular}{l|c}
\hline & Duramax/ Croma 50 \\
\hline Amarelo & - \\
\hline Azul Marinho & Bonita \\
\hline Ciano & Tranqüila, bonita \\
\hline Laranja & Forte, moderna \\
\hline Magenta & - \\
\hline
\end{tabular}

\subsection{Quanto ao iluminante}

Os observadores não notaram diferença entre a duas fontes de luz controladas, até observarem os produtos submetidos àquelas fontes. Nem mesmo quando responderam a parte correspondente à observação de cores (VELLOSO e LETA, 2002). Eles não entenderam também a razão desta diferença.

Apesar do índice de reprodução de cor ser comumente usado por indústrias, é relevante que o comércio e os consumidores percebam sua importância. O consumidor pode ser induzido a comprar produtos que não deseja por causa do IRC do iluminante.

Tabela 7 - Possibilidades de combinação de iluminante $\mathrm{x}$ escala $\mathrm{x}$ qualidade

\begin{tabular}{c|c|c}
\hline Iluminante & Escala & Qualidade \\
\hline & Muito menos & Brilhante \\
& Menos & Agradável \\
Duramax & Colorida \\
Croma 50 & Mais & Iluminada \\
& Muito Mais & Apagada \\
& & Bonita \\
\hline
\end{tabular}

$\mathrm{Na}$ Tabela 7 tem-se as possibilidades de combinação de iluminante $\mathrm{x}$ escala $\mathrm{x}$ qualidade, apresentados para os observadores.

Nas Figuras 9 e 10 apresentam-se os resultados relativos, respectivamente, às qualidades que existem e que não existem nos iluminantes, segundo a percepção dos observadores. Cabe observar que o conceito de "inexiste" agrega os seguintes termos: "muito menos" e "menos", enquanto que o conceito "existe" engloba por sua vez os termos "mais" e "muito mais". Por outro lado, o termo "neutralidade" refere-se a "igualmente". Para cada qualidade (brilhante, agradável, colorida, iluminada, apagada e bonita) tem-se uma representação em quatro barras. A primeira, mais à esquerda, refere-se à fonte Duramax, sendo a qualidade observável apresentada na Figura 9 e a não observável apresentada na Figura 10. A barra mais à direita tem o significado análogo, mas refere-se à fonte Croma 50. As duas barras centrais correspondem à neutralidade quanto à percepção, sendo que a da esquerda corresponde novamente à Duramax e a da direita à Croma 50. 


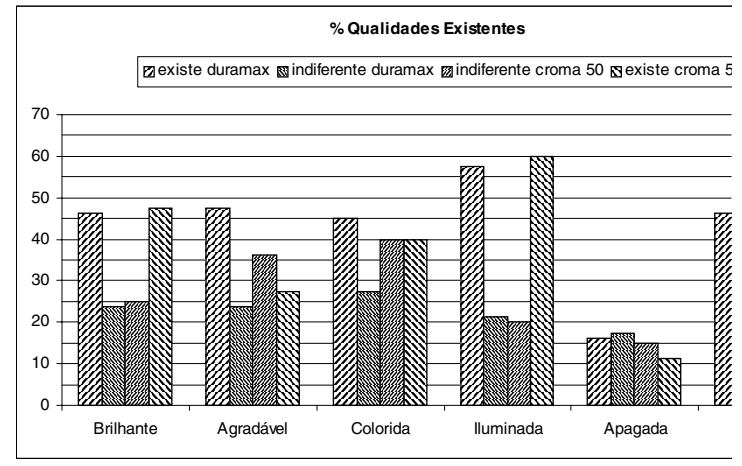

Figura 9 - Estudo do Iluminante. Qualidades que existem

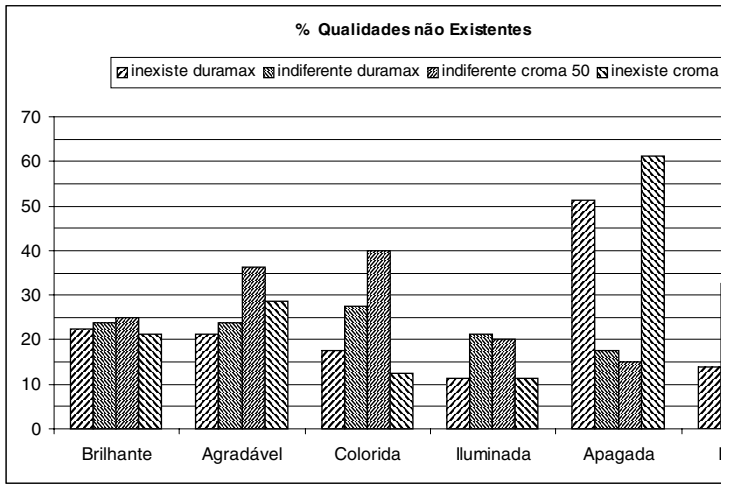

Figura 10 - Estudo do Iluminante. Qualidades que não existem

\section{Conclusões}

A partir dos resultados obtidos, na primeira fase da pesquisa (Figuras 7 e 8), pode-se observar que algumas qualidades da cor são independentes do iluminante, ou seja, a qualidade da cor é a mesma para ambos os iluminantes, como resumido a seguir:

- $\quad$ Amarelo - não é escuro nem brega;

- Azul - é bonito;

- Ciano - é bonito e tranqüilo;

- Laranja - é forte e moderno, não é escuro nem neutro;

- Magenta - não é brega nem neutro.

Por outro lado, a percepção de algumas qualidades da cor mudou quando a amostra foi submetida a diferentes iluminantes:

- $\underline{\text { Amarelo }}$ - é vívida e bonita para o Duramax, e forte para o Croma 50;

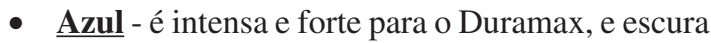
para o Croma 50;

- Ciano - é vívida, intensa e chique para o Duramax;

- Laranja - é intensa e bonita para o Duramax;

- Magenta-é vívida e intensa para o Duramax, e forte, chique, romântica e bonita para o Croma 50.
Os observadores não usaram as mesmas palavras/ qualidades para cores, como aquelas utilizadas na CIE ou nos modelos utilizados na indústria. Isso justifica mais pesquisas nesta área, explorando outros grupos de observadores e fontes de iluminação.

Os resultados obtidos a partir da prospecção de questionários dos observadores levaram às seguintes conclusões:

a) As únicas características diferentes observadas entre os iluminantes foram:

- A iluminação produzida pela lâmpada Duramax é mais agradável que a produzida pela lâmpada Croma 50.

- A iluminação produzida pela lâmpada Croma 50 não é mais apagada que a Duramax.

b) Todas as outras qualidades tiveram uma variação de até $5 \%$ entre os resultados dos dois iluminantes, tendo sido, portanto, consideradas iguais.

Um fato que chama atenção é que quando perguntados se as iluminações são igualmente agradáveis e apagadas, o enfoque em uma das lâmpadas diferir do enfoque na outra lâmpada, ou seja, os observadores 
consideraram a lâmpada Duramax mais agradável e também mais apagada do que a Croma 50. Ao mesmo tempo não observaram diferença de percepção entre os iluminantes, relacionadas às qualidades: brilhante, iluminada, colorida e bonita.

Assim, em continuidade a esta pesquisa, outras se seguirão com o intuito de verificar novas situações com diferentes lâmpadas comerciais e com grupos distintos, de acordo com a classificação por idade, sexo, grupo social e situação econômica. Com isto espera-se estabelecer parâmetros que possam auxiliar na especificação de iluminantes de modo mais adequado com respeito às diferenças de percepção de cada grupo estudado.

Em trabalhos futuros, será aplicada a lógica nebulosa para computar estes resultados, inserindo a incerteza existente na adoção de palavras que caracterizam cores, em um modelo numérico e exato. Será também avaliada a sensação que as cores provocam em diferentes grupos individuais (idades diferentes, nível de instrução diferente etc.).

Estes resultados serão importantes para comerciantes e consumidores, engenheiros e arquitetos, comércio e indústria, podendo auxiliá-los na adequação de lâmpadas para diferentes tipos de aplicação, bem como na escolha das cores mais adequadas para os objetos fabricados e comercializados.

\section{Referências}

COX, E. The Fuzzy Systems Handbook. Academic Press. 1994.

GIORGIANNI, E. J.; MADDEN, T. E. Digital Color Management. Addison-Wesley. p. 576. 1998.

JACKSON, R.; MACDONALD, L.; FREEMAN, K. Computer Generated Colour. John Wiley \& Sons. 1994.

LETA, F. R.; ARAÚJO, R. M. A Prospective Research on Using Fuzzy Sets for Determining Colour Sorting Groups More Accurately. PICS'2000, pp. 192-196. 2000.

LETA, F. R.; ARAÚJO, R. M.; VELLOSO, M.P. Qualitative Measurement of Colour Based on Human Perception. The First European Conference on Colour in Graphics, Image, and Vision, CGIV'2002, p. 585-588, 2002.

LOZANO, R. D. El color y su medición. Editorial Américalee. Argentina. 1978.

VELLOSO, M.P.; LETA, F. R. Metrologia do Consumidor: medida qualitativa de cores baseada na percepção humana dos iluminantes. LuxAmerica'2002, Argentina, 2002.

Agradecimentos: Os autores agradecem à FAPERJ pelo apoio financeiro, ao Eng. Publio Mello da General Eletric do Brasil Ltda e aos alunos do Projeto Jovens Talentos para a Ciência.

Submetido em junho/2003

Aprovado em agosto/2004 